\title{
Public attitudes toward mental illness in Africa and North America
}

\author{
KO St. Louis ${ }^{1}$, PM Roberts ${ }^{2}$ \\ ${ }^{1}$ Department of Speech Pathology and Audiology, West Virginia University, Morgantown, WW, USA \\ 2School of Rehabilitation Sciences, University of Ottawa, ON, Canada
}

\begin{abstract}
Objective: Public attitudes toward mental illness in two widely disparate cultures, Canada and Cameroon, were compared using an experimental version of a survey instrument, the Public Opinion Survey of Human Attributes-Mental IllnesS or POSHA-MI(e) Method: 120 respondents rated POSHA-MI(e) items relating to mental illness on 1-9 equal appearing interval scales: 30 in English and 30 in French in both Cameroon and Canada. Additionally, 30 matched, monolingual English, American respondents were included as a comparison group. Result: In Canada (and in the USA), attitudes were generally more positive and less socially stigmatizing toward mental illness than in Cameroon. Differences between countries were much larger than differences between language groups. Conclusion: Consistent with other research, beliefs and reactions of the public regarding mental illness reflect stigma, especially in Cameroon. Cultural influences on these public attitudes are more likely important than language influences. Results of this field test of the POSHA-MI(e), documenting differences in public attitudes toward mental illness in two divergent cultures, support its further development.
\end{abstract}

Keywords: Social stigma; Mental disorders; Language; Developing countries; Developed countries

Received: 16-12-2011

Accepted: 14-03-2012

doi: http://dx.doi.org/10.4314/ajpsy.v16i2.16

\section{Introduction}

Bohner and Dickel define an attitude as "an evaluation of an object of thought [ranging] from the mundane to the abstract, including things, people, groups, and ideas". ${ }^{1}$ Negative attitudes by the majority of people ('the public') toward individuals or characteristics of individuals give rise to stigma ${ }^{2}$ and can lead to discriminatory (and potentially illegal) behavior. Evidence indicates that negative public attitudes about a wide range of undesirable conditions can have negative impacts on the lives of people, including those with (a) mental illness ${ }^{3,4,5,6,7}$, (b) epilepsy ${ }^{8,9}$, (c) HIV/AIDS10,11, (d) obesity ${ }^{12,13}$, and (e) stuttering. 14,15,16,17 Moreover, evidence shows that that the presence of coexisting (comorbid) disorders affects stigma as well ${ }^{18,19}$, highlighting the need for considering possible interactions among multiple conditions.

Given that stigma has been shown to be widespread toward those with mental illness and other human attributes, studies have typically focused either on comparing the level of

Correspondence

Dr KO St. Louis

805 Allen Hall, PO Box 6122, West Virginia University, Morgantown,

W 26506-6122, USA

email: kstlouis@mu.edu stigma associated with various conditions across cultures or attempting to reduce or mitigate stigma. Studies have revealed different attitudes among divergent ethnic groups within the same country, e.g., the United States ${ }^{20}$ and Great Britain $^{21}$; as well as among different countries. For example, Pescasolido et al. ${ }^{22}$ compared attitudes toward different types of mental illness in five European countries, finding stigma in all of them, but in markedly different degrees. Thompson et al. ${ }^{7}$ documented that attitudes toward mental illness differed in several countries and were among the most positive in Canada. Studies of stigmatized medical conditions in African countries overwhelmingly have focused on HIV/AIDS ${ }^{23}$, but some have examined attitudes towards epilepsy ${ }^{24}$ and mental illness. ${ }^{25}$

With regard to the issue of reducing the stigma associated with mental illness, Couture and Penn ${ }^{26}$ reviewed studies focused on reducing the stigma associated with severe mental illness. They concluded that protest strategies had not been successful, that education campaigns had been moderately successful, and that direct contact (i.e., with people who were mentally ill) had been the most successful. Rabkin ${ }^{27}$ reviewed numerous studies from the 1950s to the 1970s and reported that, although numerous initiatives had resulted in some positive effects, investigators were still uncertain whether lasting reductions in stigma had occurred. 


\section{Need for comparable measures of public attitudes}

Strategies to measure attitudes have ranged from specially constructed questionnaire ${ }^{5,7}$ to open-ended interviews. ${ }^{23}$ It is not surprising, therefore, that comparing results across investigations of public attitudes, whether from cross-cultural or treatment studies, is problematic at best. Couture and Penn ${ }^{26}$ highlighted the lack of standard measures of attitudes toward mental illness as a principal hindrance to studies of attitude change. Van Brakel made a similar comment: "many stigma reduction interventions have been carried out but their effectiveness is often not known ... This is partly because tools to measure the impact have not been available, particularly in developing country settings". 28 To accurately measure stigma and to compare its contributing variables across cultures or to reliably measure change over time, instruments that have been tested in different countries and languages are needed.

\section{Issues in developing a standard measure of public attitudes toward mental illness internationally}

A long-term objective of the research initiative reported in this paper is to develop a survey instrument that can effectively measure public attitudes toward mental illness anywhere in the world. One guiding principle was that it should permit comparisons of attitudes toward mental illness with attitudes toward other human attributes in order to enhance the instrument's potential sensitivity. For example, similar mental illness attitudes in two different samples, but in the context of different attitudes toward other human attributes, would suggest that different contributing variables might be present and warrant further exploration.

We developed an English prototype of the Public Opinion Survey of Human Attributes-Mental Illness (POSHA-MI[e]) (explained in detail in the next section). We decided at the outset that a written questionnaire would provide the most reliable measure of attitudes, especially since it would require translations to widely divergent languages. In identifying mental illness for respondents, we seriously considered the use of vignettes or simulations (i.e., scenarios or descriptions of various types of mental illness, such as schizophrenia) that have been reported to enhance the face validity of associated questionnaires. 29,30

Nevertheless, vignettes containing actual audio or video samples can introduce such confounding variables as the model's dress, demeanor, race, or dialect. Pescosolido et al. ${ }^{22}$ developed culturally equivalent vignettes for a comparative study in five European countries, but the process was extremely lengthy. Although vignettes offer advantages within a single country or within similar cultural and linguistic groups, their use in comparative studies is extremely time-consuming, too often rendering them impractical. To facilitate broad use of the instrument across countries and cultures, we decided to use a written questionnaire with no descriptors of mental illness, thereby sacrificing, perhaps, some of the face validity inherent in vignettes or simulations in order to maximize the questionnaire's practicality and internal validity.

As noted, a written survey instrument requires accurate translations to other languages. Translating scales is not a simple matter ${ }^{31}$, and perfect translations are likely impossible. ${ }^{32}$ Nevertheless, we adopted four principles that foster maximally accurate renditions into other languages:

(a) avoiding sophisticated language and professional jargon,

(b) avoiding slang (e.g., "Mentally ill people are crazy"), (c) avoiding complex grammatical constructions (e.g., "I believe that mental illness means that a mentally ill person has had a curse placed upon the family"), and (d) avoiding emotionally loaded terms whose connotations may be different from their denotations (e.g., "Mental illness is caused by physical or emotional abuse").

After developing the first POSHA-MI(e) prototype, our overall strategy was to carry out a number of pilot studies, including studies designed to assess translatability, reliability, validity, and internal consistency of the instrument. Also, when sufficient data become available, our plan is to select final items using factor analysis and other strategies to arrive at a short, user-friendly questionnaire.

\section{Purpose and hypotheses}

The primary purpose of the current study was to compare public attitudes toward mental illness using the POSHA$M I(e)$ in two widely disparate cultures, Cameroon in West Africa and Canada in North America. Based on previous literature, our hypothesis was that public attitudes toward mental illness would be more positive among Canadian respondents than among Cameroonian respondents.

The study also had two secondary purposes. One was to compare attitudes in two different languages, English and French in these countries. Canada and Cameroon have significant English- and French-speaking populations living in close proximity, and speakers of both language groups were assumed to have relatively similar socio-economic characteristics. We hypothesized that the language of the survey would not significantly affect public attitudes toward mental illness.

Another secondary purpose was to compare attitudes of the bilingual/multilingual respondents in French and English with those of monolingual English-speaking respondents from the USA surveyed in previous pilot studies using an earlier version of the POSHA-MI(e). We hypothesized that differences would be much greater between countries (Cameroon versus Canada) than between languages (French versus English). We also hypothesized that American monolingual respondents and Canadians would respond more similarly than American and Cameroonian respondents, due to the greater cultural similarity between the USA and Canada compared to Cameroon and Canada.

\section{Method}

\section{POSHA-MI(e) questionnaire content}

Demographic section

The experimental version of the POSHA-MI(e) adapted for this study utilized a 1-9 Likert scale (with ? for "I don't know"). Following an instruction page which did not indicate that this was study of mental illness per se, the questionnaire began with a demographic section that asked respondents' year, city, and country of birth; city and country of residence; sex; race; religion; years of school; marital status; current job/vocation/career; income compared to all people in respondents' countries and compared to their family and associates; and self-appraisals of physical health, mental health, learning ability, and speaking ability. 


\section{General section}

Next, the general section of the POSHA-MI(e) asked for ratings about nine human attributes, i.e., about people who are/have: overweight, left handed, multilingual, old (age), stuttering, mental illness, good talkers, wheelchair use, and intelligent. The first three questions, rated on 9-point scales, reflected respondents' overall impression of each attribute, the extent to which they want to be/have each attribute, and the amount known about each attribute. The last portion in the general section was simply a checklist for individuals known who manifested mental illness and each of the other eight anchor attributes, i.e., nobody, acquaintance, close friend, distant relative, close relative, other, and/or "me" (i.e., the respondents themselves).

\section{Detailed sections}

The remainder of the POSHA-MI(e) consisted of a detailed section on mental illness requesting 77 different ratings. Items related to: (a) causes of mental illness; (b) who should help a person with mental illness; (c) degree of concern if certain people had mental illness (e.g., my child's teacher); (d) specific things the respondent would be likely to feel or do if talking to a person with mental illness (e.g., make a joke); (e) the extent to which a person with mental illness can or should do various things (e.g., lead a normal life or work in jobs requiring good judgment); (f) opinions about various characteristics of people with mental illness (e.g., are nervous and excitable); and (g) the source of the respondent's knowledge about mental illness (e.g. personal experience [me, family, friends] or television, radio, or films). Additional similar detailed sections, not reported here, asked about stuttering and multilingualism, partly to reinforce the impression that the study was not only a study of mental illness, per se, or even of negative human attributes. In this way, we hoped to avoid creating a negative response bias that could result from asking participants to think only of negative attributes or only about mental illness.

\section{Translation}

The POSHA-MI(e) was translated from English into French by the second author, a native English speaker who speaks fluent French, teaches in a bilingual university, has university training in translation, and has experience in translating and editing professional materials. Two bilingual native French speakers checked the translation. Also, after the study was completed, the completed questionnaire was submitted to two professional English-French translators for comments. No substantive problems were noted in their review A neutral, international style of French was used, avoiding colloquial and regional terms.

\section{Ethics}

The West Virginia University Institutional Review Board for protection of human subjects approved the procedures used in this study.

\section{Sampling procedures}

Canada and Cameroon respondents

The second author and a research partner-or their assistantsrecruited respondents who spoke French and/or English in the cities of Ottawa, Canada and Douala, Cameroon, respectively. In a convenience sampling paradigm, they distributed POSHA$M I(e)$ s to friends, acquaintances, or the general public, either in French or in English depending on which language potential respondents were known to prefer, or claimed was their only or their stronger language. All respondents were at least 18 years old. Completed POSHA-MI(e)s were mailed back to the first author for analysis.

Thirty respondents were sought for both languages in Canada (Cda-E, Cda-F) and in Cameroon (Cmr-E, and Cmr-F). In three samples wherein more than 30 POSHA-MI(e)s were returned (33-38), respondents were randomly eliminated to reduce the groups to 30

\section{Control respondents (USA)}

Next, from the electronic database of 680 respondents who had filled out detailed POSHA-MI(e) sections, 30 monolingual, English speaking adults (15 males and 15 females from the USA) were selected to yield a group with similar mean age and mean number of years of schooling as the Cameroon and Canada samples. Monolinguals were defined as individuals who did not list any languages known besides their native language of English and who did not check "me" under multilingual "persons known." Potential controls who identified themselves as mentally ill were also excluded.

\section{Analyses}

The 1-9 scale ratings were converted to -100 to +100 ratings wherein 0 is neutral. The reason for this is that 5 on a 1-9 scale was typically neutral. We reasoned that the positive and negative values would better communicate the results of a relatively long questionnaire.

T-tests for independent samples were run on all POSHA$M I(e)$ items for six pairs of means comparing languages within countries (Cmr-E versus Cmr-F and Cda-E versus Cda-F), countries ( $\mathrm{Cmr}$ [combined] versus Cda [combined]), language (Eng [combined] versus Fre [combined]), and controls with countries (USA versus Cmr and USA versus Cda). Since multiple t tests increase the likelihood of Type I errors, i.e., incorrectly rejecting the null hypothesis, we utilized the Bonferroni correction, i.e., dividing the alpha level by the number of comparisons. ${ }^{33}$ This yielded a critical value of $\mathrm{p}<.00417$ ( $\mathrm{p}$ .05 by 12 or the approximate average number of items following each prompt).

\section{Results}

\section{Demographic}

Table I summarizes selected demographic characteristics of the four language groups and the control group. The mean ages for the four groups of Cameroonian and Canadian respondents were between 31 and 41 years. Age ranges were similar, although the Cmr-E group was the youngest on average but also had the oldest respondent. Respondents were generally well educated, with mean total years of schooling ranging from 16.2 years to 14.5 years. Arbitrary composite scores of the relative incomes of the respondents revealed that the two language groups in each country were quite similar (25 and 24 for Canada versus - 14 and - 10 for Cameroon) but were quite different between the two countries (25 and -14 for English versus 24 and -10 for French), supporting our assumption that that English and French speakers in each country had similar socio-economic characteristics.

One and two respondents in the Cda-E and Cda-F groups, respectively, indicated that they were mentally ill. One in the latter group was a wheelchair user. Converted scaled ratings 


\begin{tabular}{|c|c|c|c|c|c|}
\hline & Cmr-E & Cmr-F & Cda-E & $C d a-F$ & USA \\
\hline Number in sample & 30 & 30 & 30 & 30 & 30 \\
\hline Mean age (years) & 31.0 & 35.4 & 40.5 & 38.3 & 42.4 \\
\hline Range of ages (years) & $19.0-80.0$ & 23.0-65.0 & $20.2-63.4$ & $21.2-67.3$ & $20.3-67.8$ \\
\hline Sex: Males/females (\%) & $62.1 / 37.9$ & $75.0 / 25.0$ & $55.1 / 44.8$ & $46.7 / 53.3$ & $50.0 / 50.0$ \\
\hline Mean total schooling (years) & 15.1 & 14.5 & 15.2 & 16.2 & 15.1 \\
\hline Mean income relative to family/friends \& others in country $(-100$ to +100$)$ & -14 & -10 & 25 & 24 & $\overbrace{}^{\mathrm{a}}$ \\
\hline $\begin{array}{l}\text { Living Arrangement (\% responding) } \\
\text { Single } \\
\text { Engaged or married } \\
\text { Separated or divorced } \\
\text { Other }\end{array}$ & \begin{tabular}{|l}
55.2 \\
34.5 \\
0 \\
10.3
\end{tabular} & $\begin{array}{l}29.0 \\
42.1 \\
7.9 \\
21.1\end{array}$ & $\begin{array}{l}17.1 \\
45.7 \\
22.9 \\
14.3\end{array}$ & $\begin{array}{l}34.4 \\
28.1 \\
15.6 \\
21.9\end{array}$ & $\begin{array}{l}21.9 \\
59.4 \\
12.5 \\
6.3\end{array}$ \\
\hline $\begin{array}{l}\text { Race (\% total) } \\
\text { Caucasian/White/Canadian/French/North American/Quebecois/European } \\
\text { African/Black African/Negro } \\
\text { Asian } \\
\text { North American Indian } \\
\text { Other } \\
\text { Not given }\end{array}$ & $\begin{array}{l}0 \\
90.0 \\
0 \\
0 \\
3.3^{c} \\
10.0\end{array}$ & $\begin{array}{l}0 \\
93.3^{b} \\
0 \\
0 \\
0 \\
6.7\end{array}$ & $\begin{array}{l}86.7 \\
0 \\
3.3 \\
0 \\
6.7 \\
3.3\end{array}$ & $\begin{array}{l}76.7 \\
0 \\
0 \\
3.3 \\
0 \\
20.0\end{array}$ & $\begin{array}{l}90.0 \\
6.7 \\
3.3 \\
0 \\
0 \\
3.3\end{array}$ \\
\hline $\begin{array}{l}\text { Religion (\% total) } \\
\text { Christian } \\
\text { Jewish } \\
\text { Muslim } \\
\text { Atheist } \\
\text { Animistic } \\
\text { Other } \\
\text { None given }\end{array}$ & \begin{tabular}{|l|}
90.0 \\
0 \\
3.3 \\
0 \\
0 \\
0 \\
6.7
\end{tabular} & $\begin{array}{l}83.3 \\
0 \\
3.3 \\
0 \\
6.7 \\
0 \\
6.7\end{array}$ & $\begin{array}{l}60.0 \\
0 \\
3.3 \\
16.7 \\
0 \\
3.3 \\
16.7\end{array}$ & $\begin{array}{l}63.3 \\
0 \\
0 \\
26.7 \\
0 \\
3.3 \\
6.7\end{array}$ & $\begin{array}{l}73.3 \\
13.3 \\
3.3 \\
3.3 \\
0 \\
0 \\
6.7\end{array}$ \\
\hline $\begin{array}{l}\text { Self-identification (\% total) } \\
\text { Mentally ill } \\
\text { Stuttering } \\
\text { Wheelchair user } \\
\text { Overweight } \\
\text { Old } \\
\text { Left handed } \\
\text { Multilingual } \\
\text { Good talker } \\
\text { Intelligent }\end{array}$ & \begin{tabular}{|l}
0 \\
0 \\
0 \\
0 \\
0 \\
3.3 \\
43.3 \\
13.3 \\
30.0
\end{tabular} & $\begin{array}{l}0 \\
0 \\
0 \\
3.3 \\
3.3 \\
3.3 \\
36.7 \\
43.3 \\
30.0\end{array}$ & $\begin{array}{l}3.3 \\
0 \\
0 \\
16.7 \\
3.3 \\
6.7 \\
36.7 \\
40.0 \\
53.3\end{array}$ & $\begin{array}{l}6.7 \\
0 \\
3.3 \\
20.0 \\
6.7 \\
13.3 \\
66.7 \\
46.7 \\
66.7\end{array}$ & $\begin{array}{l}0 \\
0 \\
0 \\
26.7 \\
10.0 \\
13.3 \\
0 \\
20.0 \\
46.7\end{array}$ \\
\hline $\begin{array}{l}\text { Mean self-rating of health \& abilities (ratings converted to }-100 \text { to }+100 \text { ) } \\
\text { Physical health } \\
\text { Mental health } \\
\text { Ability to learn } \\
\text { Speaking ability }\end{array}$ & \begin{tabular}{|l|}
67.6 \\
80.8 \\
72.6 \\
80.0
\end{tabular} & $\begin{array}{l}50.8 \\
69.4 \\
51.0 \\
53.4\end{array}$ & $\begin{array}{l}39.6 \\
58.6 \\
71.6 \\
70.6\end{array}$ & $\begin{array}{l}50 \\
69.2 \\
73.4 \\
72.6\end{array}$ & $\begin{array}{l}42.6 \\
52.0 \\
58.0 \\
54.2\end{array}$ \\
\hline Mean time taken to complete POSHA-MI(e) (min) & 87.0 & 282.0 & 29.0 & 47.2 & $\mathrm{na}^{\mathrm{d}}$ \\
\hline Range of time taken to complete $P O S H A-M I(e)(\mathrm{min})$ & $30-330$ & $25-4295$ & $10-75$ & $20-90$ & $n^{d}$ \\
\hline \multicolumn{6}{|c|}{$\begin{array}{l}\text { a Relative income was not included in the first prototype of the POSHA-MI(e). } \\
\text { b36.7\% also indicated tribe: Bamileke, Bamoun, Bassa, Bayangi, Beti, Mineeh, and Nso. } \\
\text { 'Did not identify race. } \\
\text { dNo estimate reported since only a few respondents recorded their response time. }\end{array}$} \\
\hline
\end{tabular}


$(-100$ to +100$)$ for physical health of the four groups ranged from 43-68; for mental health, from 52-81; for ability to learn, 51-73; and for speaking ability, 53-80.

The largest differences observed between any of the groups were for the time required to complete the POSHA$M I(e)$ (plus detailed sections relating to stuttering and multilingualism). French speaking Cameroonians required a mean of nearly five hours to complete the questionnaire with a range of 25 minutes to an astonishing 72 hours. Even without the extreme outlier, the group mean was more than 2 hours. The English speaking Cameroonians required a mean of nearly 1 l/2 hours with a range of $1 / 2$ hour to 5 l/2 hours. This compares to a mean of 47 and 29 minutes for the French and English speaking Canadians, respectively, whose ranges were 20-90 minutes and 10-75 minutes. Most of the controls in the early studies were not asked for their reporting time.

\section{Country and language comparisons}

Percentage of t-test comparisons

Table II summarizes the number and percentages of significant differences $(\mathrm{p} \leq 0.00417)$ on general and detailed mental illness items for the following group pairs:

(a) English versus French speakers in Cameroon, (b) English versus French speakers in Canada, (c) all Cameroonians versus all Canadians, (d) English versus French speakers in both Cameroon and Canada, (e) Americans versus Cameroonians, and (f) Americans versus Canadians. As hypothesized, a substantial percentage of significant comparisons for mental illness items (39.4\%) occurred between combined Cameroon versus Canada comparisons, with Cohen's d effect sizes ${ }^{34}$ between .55 to 2.32 ( $\mathrm{M}=1.12$ ) ("large" to very large). Similarly, USA control group comparisons with the two country groups also confirmed initial hypotheses: $32.7 \%$ of the significant differences occurred between American and Cameroonian respondents (effect sizes from .50-2.63; $\mathrm{M}=1.07$; mostly "large" to very large) versus only $8.2 \%$ between American and Canadian respondents (effect sizes from .68 - 1.22; $\mathrm{M}=$ .89; mostly "medium" and "large"). By contrast, and also as hypothesized, the percentages of significantly different comparisons between English and French respondents in either Cameroon or Canada were only 3.9 and $4.9 \%$, respectively, of the total ratings. Cohen's d effect sizes for these few items ranged from .80 to $.1 .03(\mathrm{M}=.89$ and 1.00 , respectively) or within the "large" effect range (i.e., > .8). Similarly, when the language data for both countries were combined, few French to English comparisons were significantly different (7.7\% of the pairs). Effects sizes for these comparisons ranged from .55 to .86 with most in the "moderate" range $(\mathrm{M}=.64)$

\section{POSHA-MI(e) item differences for country and language} The first 27 items in Table II pertain to the general section that compares mental illness with eight other attributes. Cameroonians had significantly worse overall impressions of persons with mental illness than Canadians. Otherwise, there were no differences for mental illness for any of the comparisons by language and/or country. By contrast, several comparisons were different for other attributes, primarily between Cameroon and Canada or between USA
Figure 1: Attitudes related to mental illness in comparison to eight other human attributes: Respondents from Canada versus Cameroon combined, from English speakers versus French speakers combined, and from monolingual USA control respondents.

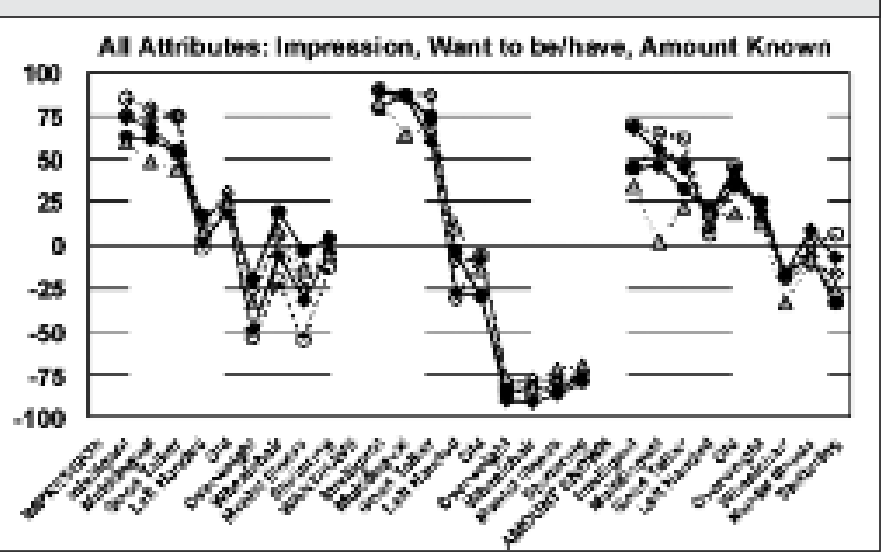

and Cameroon. Not surprisingly, as seen in Figure 1, monolingual USA respondents reported lower scores for wanting to be multilingual and knowing less about multilingualism than Canadians or Cameroonians.

The next nine items in Table II pertain to sources of information about mental illness. Contrary to the vast majority of significant differences across all items, information coming from personal experience with mental illness, experience with others with mental illness, or family and friends were least and significantly less likely to be identified by the USA control group than by Canadians, who had the highest ratings. Canadians also had significantly higher scores for family and friends as an information source than Cameroonians. These data for source of information are also shown graphically in the left side grouping of items in Figure 2 .

The next 11 items in Table II summarize respondents' views of the causes of mental illness. Generally, for the first six items, Canadians and Americans had higher mean ratings than Cameroonians, significantly so for genetic, learning/habits, and physical/body function etiologies. The

Figure 2: Attitudes related to sources of information and causes of mental illness. Respondents from Canada versus Cameroon combined, from English speakers versus French speakers combined, and from monolingual USA control respondents.

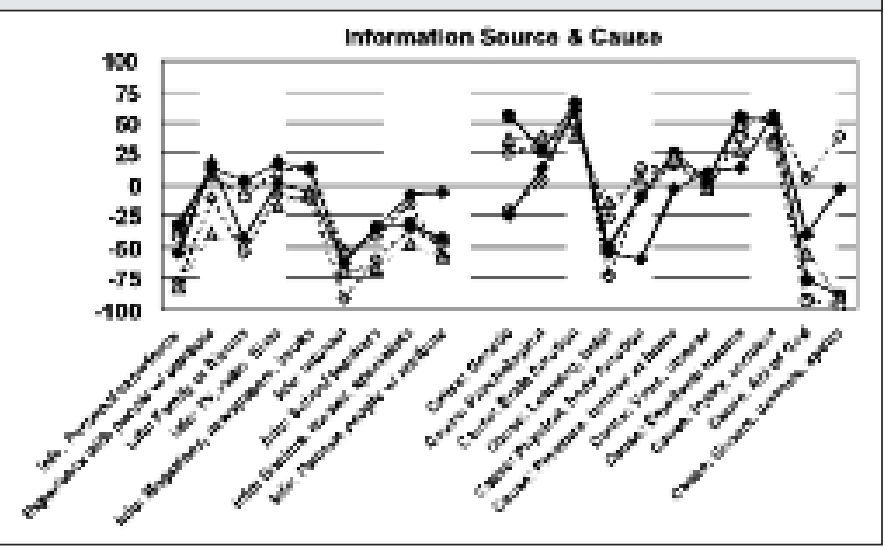


Table II: Mean and statistical comparisons among respondents according to country (Canada or Cameroon) and language (English or French) as well as comparison with a control group from the USA.

\begin{tabular}{|c|c|c|c|c|c|c|c|c|c|c|c|c|}
\hline POSHA-MI(e) Item & Column & 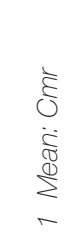 & 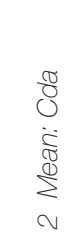 & 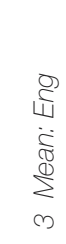 & $\begin{array}{l}\frac{0}{4} \\
\stackrel{\Phi}{\Phi} \\
\sum_{\forall}^{\infty} \\
\forall\end{array}$ & 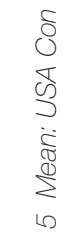 & $\begin{array}{l}\grave{E} \\
\overrightarrow{0} \\
\overrightarrow{8} \\
0 \\
0\end{array}$ & $\begin{array}{l}\text { हे } \\
\overrightarrow{0} \\
\vec{J} \\
\text { J } \\
\wedge\end{array}$ & $\begin{array}{l}8 \\
8 \\
0 \\
> \\
\text { S } \\
\infty \\
\infty\end{array}$ & $\begin{array}{l}\text { U. } \\
\text { है } \\
\text { ग } \\
\text { फे } \\
\text { है } \\
0 \\
0\end{array}$ & 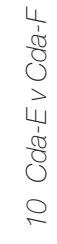 & 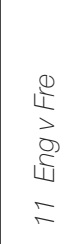 \\
\hline $\begin{array}{l}\text { GENERAL ITEMS } \\
\text { My overall impression of a person who is/has... } \\
\text { Intelligent } \\
\text { Multilingual } \\
\text { Good talker } \\
\text { Left handed } \\
\text { Old } \\
\text { Overweight } \\
\text { Wheelchair } \\
\text { Stuttering } \\
\text { Mentally ill }\end{array}$ & & $\begin{array}{l}-13 \\
75 \\
-21 \\
79 \\
-2 \\
85 \\
-55 \\
25 \\
-54\end{array}$ & $\begin{array}{l}4 \\
54 \\
19 \\
62 \\
17 \\
63 \\
-3 \\
25 \\
-20\end{array}$ & $\begin{array}{l}-5 \\
55 \\
-6 \\
68 \\
3 \\
74 \\
-32 \\
19 \\
-50\end{array}$ & $\begin{array}{l}-4 \\
74 \\
5 \\
73 \\
12 \\
76 \\
-25 \\
30 \\
-26\end{array}$ & \begin{tabular}{|l}
-6 \\
43 \\
8 \\
48 \\
8 \\
59 \\
-14 \\
24 \\
-33
\end{tabular} & \begin{tabular}{|l} 
* \\
* \\
* \\
* \\
*
\end{tabular} & * & & & & \\
\hline $\begin{array}{l}\text { I would want to be/have... } \\
\text { Intelligent } \\
\text { Multilingual } \\
\text { Good talker } \\
\text { Left handed } \\
\text { Old } \\
\text { Overweight } \\
\text { Wheelchair } \\
\text { Stuttering } \\
\text { Mental Illness }\end{array}$ & & $\begin{array}{l}-79 \\
74 \\
-86 \\
87 \\
-31 \\
90 \\
-81 \\
-5 \\
-83\end{array}$ & $\begin{array}{l}-73 \\
73 \\
-83 \\
87 \\
-4 \\
79 \\
-85 \\
-30 \\
-86\end{array}$ & $\begin{array}{l}-79 \\
60 \\
-92 \\
86 \\
-27 \\
89 \\
-87 \\
-30 \\
-89\end{array}$ & $\begin{array}{l}-74 \\
86 \\
-79 \\
87 \\
-10 \\
80 \\
-79 \\
-8 \\
-79\end{array}$ & \begin{tabular}{|l}
-70 \\
68 \\
-83 \\
64 \\
10 \\
83 \\
-72 \\
-14 \\
-77
\end{tabular} & * & * & & & & \\
\hline $\begin{array}{l}\text { Amount I know about people who are/have... } \\
\text { Intelligent } \\
\text { Multilingual } \\
\text { Good talker } \\
\text { Left handed } \\
\text { Old } \\
\text { Overweight } \\
\text { Wheelchairs } \\
\text { Stuttering } \\
\text { Mentally ill }\end{array}$ & & $\begin{array}{l}6 \\
62 \\
-19 \\
65 \\
7 \\
69 \\
0 \\
46 \\
14\end{array}$ & $\begin{array}{l}-33 \\
33 \\
-17 \\
46 \\
21 \\
44 \\
-7 \\
34 \\
25\end{array}$ & $\begin{array}{l}-7 \\
45 \\
-17 \\
54 \\
19 \\
68 \\
8 \\
44 \\
20\end{array}$ & $\begin{array}{l}-17 \\
49 \\
-19 \\
56 \\
10 \\
46 \\
-12 \\
36 \\
20\end{array}$ & $\begin{array}{l}-26 \\
23 \\
-34 \\
2 \\
18 \\
34 \\
-8 \\
18 \\
12\end{array}$ & * & $\begin{array}{l}\text { * } \\
\text { * } \\
\text { * } \\
\text { * }\end{array}$ & * & * & & * \\
\hline $\begin{array}{l}\text { DETAILED MENTAL ILLNESS ITEMS } \\
\text { My information about mental illness comes from... } \\
\text { Personal experience with mental illness } \\
\text { Experience with other people who are mentally ill } \\
\text { Family or friends } \\
\text { Info from: TV, radio, films } \\
\text { Magazines, newspapers, books } \\
\text { Internet } \\
\text { School teachers } \\
\text { Doctors, nurses, specialists } \\
\text { Famous people with mental illness }\end{array}$ & & $\begin{array}{l}-67 \\
4 \\
-49 \\
-3 \\
-9 \\
-77 \\
-47 \\
-22 \\
-25\end{array}$ & $\begin{array}{l}-37 \\
10 \\
-4 \\
14 \\
12 \\
-58 \\
-38 \\
-23 \\
-50\end{array}$ & $\begin{array}{l}-44 \\
15 \\
-21 \\
10 \\
3 \\
-63 \\
-34 \\
-19 \\
-23\end{array}$ & $\begin{array}{l}-60 \\
-1 \\
-31 \\
2 \\
0 \\
-72 \\
-50 \\
-25 \\
-53\end{array}$ & $\begin{array}{l}-82 \\
-39 \\
-49 \\
-17 \\
-6 \\
-69 \\
-66 \\
-47 \\
-59\end{array}$ & * & & $\begin{array}{l}\text { * } \\
\text { * } \\
\text { * }\end{array}$ & & & \\
\hline $\begin{array}{l}\text { The cause of mental illness is... } \\
\text { Genetic } \\
\text { Psychological } \\
\text { Brain function } \\
\text { Learning, habit } \\
\text { Physical or body function } \\
\text { Pressure, tension at home } \\
\text { Virus, disease } \\
\text { Emotional trauma } \\
\text { Injury, accident } \\
\text { Act of God } \\
\text { Ghosts, demons, spirits }\end{array}$ & & $\begin{array}{l}-23 \\
10 \\
63 \\
-63 \\
-35 \\
7 \\
7 \\
31 \\
56 \\
-17 \\
16\end{array}$ & $\begin{array}{l}40 \\
30 \\
57 \\
-38 \\
2 \\
21 \\
0 \\
47 \\
43 \\
-85 \\
-93\end{array}$ & $\begin{array}{l}15 \\
21 \\
62 \\
-53 \\
-34 \\
11 \\
7 \\
35 \\
54 \\
-58 \\
-45\end{array}$ & $\begin{array}{l}4 \\
21 \\
57 \\
-46 \\
2 \\
18 \\
1 \\
43 \\
46 \\
-45 \\
-35\end{array}$ & $\begin{array}{l}37 \\
38 \\
40 \\
-14 \\
4 \\
22 \\
-3 \\
27 \\
36 \\
-56 \\
-90\end{array}$ & * & $\begin{array}{l}\text { * } \\
\text { * } \\
\text { * }\end{array}$ & & * & & \\
\hline $\begin{array}{l}\text { A person with mental illness should be helped by... } \\
\text { The person him(her)self with mental illness } \\
\text { Others with mental illness } \\
\text { Medical doctor, pediatrician } \\
\text { Religious leader } \\
\text { Physical/occupational therapist } \\
\text { The person's family } \\
\text { Psychologist, psychiatrist, counselor } \\
\text { Institution for mentally ill } \\
\text { Special care home for mentally ill }\end{array}$ & & $\begin{array}{l}-94 \\
-92 \\
29 \\
-4 \\
-8 \\
17 \\
46 \\
68 \\
71\end{array}$ & $\begin{array}{l}14 \\
-32 \\
59 \\
-38 \\
1 \\
29 \\
79 \\
53 \\
58\end{array}$ & $\begin{array}{l}-31 \\
-51 \\
65 \\
6 \\
15 \\
34 \\
62 \\
66 \\
62\end{array}$ & \begin{tabular}{|l}
-53 \\
-74 \\
25 \\
-49 \\
-23 \\
12 \\
64 \\
56 \\
66
\end{tabular} & $\begin{array}{l}14 \\
-25 \\
77 \\
10 \\
4 \\
36 \\
72 \\
36 \\
35\end{array}$ & $\begin{array}{l}* \\
* \\
*\end{array}$ & $\begin{array}{l}* \\
* \\
* \\
*\end{array}$ & * & * & $\begin{array}{l}\text { * } \\
\text { * } \\
\text { * }\end{array}$ & $\star$ \\
\hline
\end{tabular}


Table II: Mean and statistical comparisons among respondents according to country (Canada or Cameroon) and language (English or French) as well as comparison with a control group from the USA. CONTINUED

\begin{tabular}{|c|c|c|c|c|c|c|c|c|c|c|c|}
\hline POSHA-MI(e) Item & 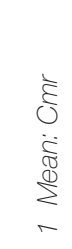 & 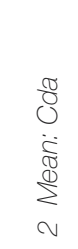 & 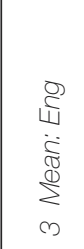 & $\begin{array}{l}\frac{0}{1} \\
\stackrel{\Phi}{\Phi} \\
\sum \\
\sum \\
\forall\end{array}$ & 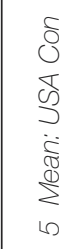 & $\begin{array}{l}\text { हे } \\
\text { J } \\
\vec{~} \\
\mathbb{8} \\
0 \\
0\end{array}$ & $\begin{array}{l}\text { हे } \\
\text { गे } \\
\vec{~} \\
\text { गे } \\
\wedge\end{array}$ & $\begin{array}{l}\mathbb{8} \\
0 \\
> \\
\mathbb{1} \\
D \\
\infty\end{array}$ & $\begin{array}{l}\frac{1}{1} \\
\text { है } \\
0 \\
د \\
\frac{1}{1} \\
\text { है } \\
0 \\
0\end{array}$ & $\begin{array}{l}4 \\
\frac{1}{8} \\
8 \\
0 \\
> \\
4 \\
\frac{1}{8} \\
8 \\
0 \\
0 \\
2\end{array}$ & $\begin{array}{l}\text { Q } \\
\frac{1}{3} \\
\text { g } \\
\text { w } \\
= \\
=\end{array}$ \\
\hline $\begin{array}{l}\text { If I were talking with a person with mental illness I would... } \\
\text { Ignore mental illness } \\
\text { Tell person it's OK to have mental illness } \\
\text { Tell person to stop acting mentally ill } \\
\text { Joke about mental illness } \\
\text { Walk away } \\
\text { Hit or slap person } \\
\text { Say "Slow down/Relax" } \\
\text { Imitate the mental illness } \\
\text { Find another to speak for the person }\end{array}$ & $\begin{array}{l}-16 \\
-62 \\
-55 \\
-77 \\
-32 \\
-85 \\
17 \\
-83 \\
-22\end{array}$ & $\begin{array}{l}0 \\
-20 \\
-83 \\
-83 \\
-77 \\
-100 \\
-74 \\
-100 \\
-68\end{array}$ & $\begin{array}{l}-8 \\
-51 \\
-70 \\
-75 \\
-64 \\
-94 \\
-35 \\
-92 \\
-60\end{array}$ & $\begin{array}{l}-8 \\
-31 \\
-66 \\
-85 \\
-45 \\
-91 \\
-25 \\
-91 \\
-31\end{array}$ & \begin{tabular}{|l}
6 \\
-53 \\
-96 \\
-97 \\
-90 \\
-97 \\
-78 \\
-96 \\
-83
\end{tabular} & $\begin{array}{l}\text { * } \\
\text { * } \\
\text { * } \\
\text { * }\end{array}$ & $\begin{array}{l}\text { * } \\
\text { * } \\
\text { * } \\
\text { * } \\
\text { * }\end{array}$ & * & & & \\
\hline $\begin{array}{l}\text { If I were talking with a person with mental illness I would feel... } \\
\text { Surprised } \\
\text { Embarrassed } \\
\text { Frustrated } \\
\text { Impatient } \\
\text { Annoyed, angry } \\
\text { Comfortable or relaxed } \\
\text { Relieved } \\
\text { Curious to know more about mental illness } \\
\text { Afraid } \\
\text { Pity }\end{array}$ & $\begin{array}{l}-42 \\
-46 \\
-44 \\
-25 \\
-68 \\
-25 \\
-30 \\
24 \\
-60 \\
68\end{array}$ & $\begin{array}{l}-54 \\
-57 \\
-51 \\
-51 \\
-77 \\
7 \\
-49 \\
21 \\
-85 \\
-21\end{array}$ & $\begin{array}{l}-59 \\
-63 \\
-42 \\
-33 \\
-74 \\
-7 \\
-33 \\
22 \\
-70 \\
40\end{array}$ & $\begin{array}{l}-37 \\
-40 \\
-54 \\
-44 \\
-71 \\
-10 \\
-46 \\
23 \\
-75 \\
7\end{array}$ & $\begin{array}{l}-54 \\
-57 \\
-47 \\
-47 \\
-74 \\
0 \\
-66 \\
19 \\
-74 \\
-2\end{array}$ & * & * & & & & \\
\hline $\begin{array}{l}\text { If ... was mentally ill, I would be concerned or worried } \\
\text { My neighbor } \\
\text { My child's teacher } \\
\text { My child's friend } \\
\text { My husband or wife } \\
\text { My doctor } \\
\text { My religious leader } \\
\text { My son } \\
\text { My daughter } \\
\text { I (myself) }\end{array}$ & $\begin{array}{l}55 \\
68 \\
65 \\
90 \\
74 \\
70 \\
95 \\
94 \\
84\end{array}$ & $\begin{array}{l}-9 \\
57 \\
37 \\
76 \\
68 \\
9 \\
79 \\
79 \\
81\end{array}$ & $\begin{array}{l}31 \\
61 \\
57 \\
93 \\
82 \\
61 \\
97 \\
98 \\
94\end{array}$ & $\begin{array}{l}15 \\
65 \\
45 \\
74 \\
59 \\
16 \\
77 \\
76 \\
70\end{array}$ & $\begin{array}{l}13 \\
72 \\
45 \\
64 \\
75 \\
40 \\
78 \\
78 \\
83\end{array}$ & * & & & & $\begin{array}{l}* \\
\text { * }\end{array}$ & $\begin{array}{l}\text { * } \\
\text { * } \\
\text { * } \\
\text { * } \\
\text { * }\end{array}$ \\
\hline $\begin{array}{l}\text { People with mental illness ... } \\
\text { Can interact socially } \\
\text { Can make friends } \\
\text { Can do well in school } \\
\text { Can raise a family } \\
\text { Can get a job } \\
\text { Can do well at work } \\
\text { Can do any job they want } \\
\text { Can lead a normal life } \\
\text { Can communicate effectively } \\
\text { Are less intelligent than normal } \\
\text { Are nervous or excitable } \\
\text { Are shy or fearful } \\
\text { Are pleasant to be around } \\
\text { Are no different from others } \\
\text { Should hide their mental illness } \\
\text { Should get help } \\
\text { Should have a job requiring lots of talking } \\
\text { Should have a job requiring good judgment } \\
\text { Should have a job requiring earning people's trust } \\
\text { Should have an influential job }\end{array}$ & $\begin{array}{l}-47 \\
3 \\
-56 \\
-26 \\
-58 \\
-54 \\
-70 \\
-41 \\
-55 \\
5 \\
20 \\
-20 \\
-30 \\
-32 \\
-37 \\
72 \\
-87 \\
-65 \\
-61 \\
-91\end{array}$ & $\begin{array}{l}40 \\
65 \\
52 \\
50 \\
56 \\
56 \\
19 \\
38 \\
17 \\
-61 \\
-11 \\
-15 \\
24 \\
7 \\
-68 \\
75 \\
-16 \\
-25 \\
-12 \\
-30\end{array}$ & \begin{tabular}{|l}
-4 \\
28 \\
-7 \\
17 \\
-7 \\
-10 \\
-27 \\
-3 \\
-32 \\
-22 \\
7 \\
-24 \\
-3 \\
-17 \\
-50 \\
71 \\
-55 \\
-43 \\
-31 \\
-54
\end{tabular} & \begin{tabular}{|l}
-2 \\
41 \\
3 \\
13 \\
6 \\
14 \\
-21 \\
3 \\
-6 \\
-33 \\
2 \\
-10 \\
-3 \\
-9 \\
-56 \\
76 \\
-50 \\
-48 \\
-43 \\
-69
\end{tabular} & \begin{tabular}{|l}
-26 \\
-27 \\
-22 \\
-21 \\
-23 \\
-14 \\
-7 \\
16 \\
7 \\
-49 \\
14 \\
18 \\
5 \\
-16 \\
-35 \\
59 \\
-20 \\
-19 \\
-8 \\
-38
\end{tabular} & $\begin{array}{l}* \\
* \\
* \\
* \\
* \\
* \\
* \\
* \\
* \\
* \\
* \\
* \\
* \\
* \\
* \\
* \\
* \\
* \\
*\end{array}$ & $\begin{array}{l}\text { naa } \\
\text { naa } \\
n a^{a} \\
n a^{a} \\
n a^{a} \\
n a^{a} \\
\star \\
\star \\
\star \\
\text { * }\end{array}$ & $\begin{array}{l}\text { na } \\
\text { na } \\
n a^{a} \\
n a^{a} \\
n a^{a} \\
n a^{a}\end{array}$ & * & & \\
\hline Total Significant $(\mathrm{n}=98)$ & & & & & & 41 & 32 & 8 & 4 & 5 & 8 \\
\hline Percent Significant & & & & & & $39.4 \%$ & $32.7 \%$ & $8.2 \%$ & $3.9 \%$ & $4.9 \%$ & $7.7 \%$ \\
\hline \multicolumn{12}{|c|}{$\begin{array}{l}\text { Notes: All POSHA-MI(e) items (wording abbreviated) are followed in each case by means of all ratings for countries (Cameroon [Column 1] and Canada [Column 2]), } \\
\text { languages (English [Column 3] and French [Column 4]), and controls (USA monolingual [Column 5]). 1-9 ratings are converted to -100 to +100 with } 0=\text { neutral. (Most USA } \\
\text { respondents utilized a different, quasi-continuous rating scales, i.e., vertical marks placed on horizontal lines that were late converted to } 0-100 \text { ratings with custom rulers.) } \\
\text { Statistically significant difference t tests between all pair-wise comparisons are shown as asterisks ( }{ }^{*} \text { ) (p } \leq .00417 \text { using the Bonferroni correction) for six pair-wise } \\
\text { comparisons for POSHA-Ml items: between combined samples in the two countries (Column 6), and between USA monolingual controls and combined Cameroonian } \\
\text { (Column 7) and Canadian (Column 8) respondents, between English versus French speakers in Cameroon (Column 9) and Canada (Column 10), between combined samples } \\
\text { in the two languages (Column 11), } \\
\text { aComparisons with the control group since problems were impossible because wording of these items in the early studies were changed, rendering them non-comparable to } \\
\text { the data in this study. }\end{array}$} \\
\hline
\end{tabular}


reverse was true for perceived etiologies of viruses/disease, and act of God, or ghosts/demons/spirits (with higher ratings from the Cameroonians). The right side of Figure 2 shows relative beliefs for different causes of mental illness listed on the POSHA-MI(e). Ratings tended to be generally quite high (and therefore more accurate) for genetic and brain function causes and low (and more accurate) for learning/habits. By contrast, views of mental illness causation appeared to be quite high for psychological (possibly inaccurate), pressure/tension at home (likely inaccurate), emotional trauma (possibly accurate), and injury/accident (unlikely accurate). Respondents also did not soundly reject virus/disease as a cause for mental illness (very likely inaccurate).

Nine items identified potential sources of help for those with mental illness (Table II and the left side of Figure 3). The first two items, helping oneself and seeking help from others with mental illness, received significantly higher ratings in Canada and the USA than in Cameroon (but still not strongly positive). Canadians and Americans, respectively, had significantly higher ratings than

Cameroonians for advocating help from a psychologist/psychiatrist/counselor and special care home for mentally ill persons. There were differences between language groups on three items: help from a medical doctor/pediatrician, a religious leader, and the person's family.

Figure 3: Attitudes related to sources of help for mental illness and what one would do when conversing with a person who is mentally ill. Respondents from Canada versus Cameroon combined, from English speakers versus French speakers combined, and from monolingual USA control respondents.

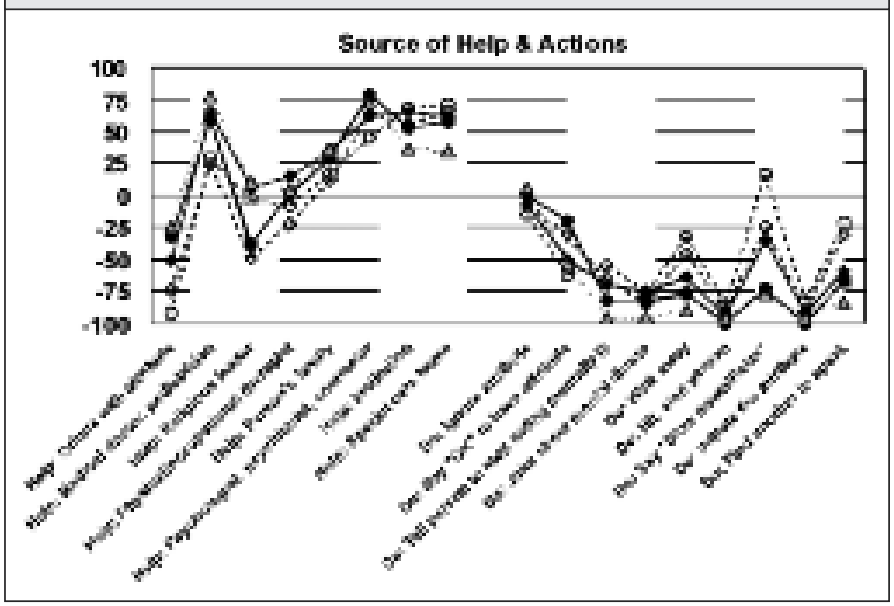

The next nine items in Table II and right side of Figure 3 relate to what respondents believed they would do when talking with a person with mental illness. For most of the negative or stigmatizing reactions, i.e., telling the person to stop acting as if he or she was mentally ill, making a joke about mental illness, walking away, hitting or slapping the person, saying "Slow down" or "Relax," imitating some aspect of the mental illness, or going to find someone else to speak to the person, Canadians and/or Americans were significantly less likely than
Cameroonians to indicate that they would engage in those behaviors. Surprisingly, USA respondents were significantly different from Canadian respondents on two of these items, even though the means were near the lowest possible scores, i.e., - 100. One item differed from this pattern. Cameroonians were less likely to tell a conversation partner that it is okay to be mentally ill than were Canadians or Americans, significantly so for the Canadians.

Ten items dealt with what respondents would feel when talking with a person with mental illness (Table II and left side of Figure 4). A similar pattern emerged for what respondents would do obtained for these items as well, but there were significant between-group differences for only one item, i.e., feeling pity. For surprise,

embarrassment, frustration, annoyance/anger, fear, and relief, there was a trend for lower scores for Canadians and Americans (and higher scores for comfort/relaxation) compared to Cameroonians. There was little difference for curiosity about mental illness.

Figure 4: Attitudes related to what one would feel when conversing with a person who is mentally ill and concern if various persons were mentally ill: Respondents from Canada versus Cameroon combined, from English speakers versus French speakers combined, and from monolingual USA control respondents.

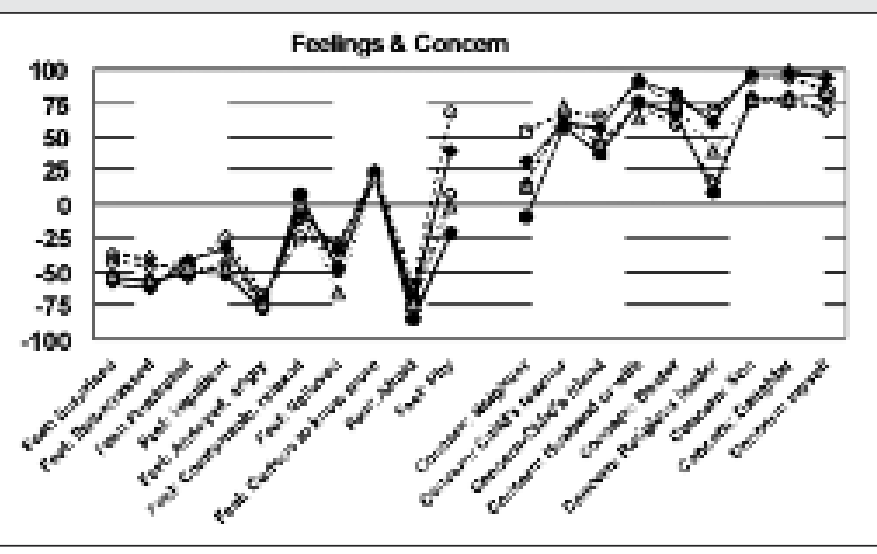

Nine items identified a potential hierarchy of concern if various persons were mentally ill. These results, shown in the table and right side of Figure 4 were somewhat complex. Canadians were significantly less likely than Cameroonians to be concerned if a neighbor or a religious leader was mentally ill. In a different vein, ratings for concern if one's spouse, doctor, religious leader, son, or daughter was mentally ill showed significant differences between English and French speakers from both countries combined, as well as from English versus French Canadian speakers for one's doctor.

The remainder of the POSHA-MI(e) items in Table II relate to beliefs about a hypothetical person with mental illness. Nine items relate to what such a person can do or achieve, five items describe such a person, and six items pertain to what such a person should do.

All nine items describing abilities and potential for a person with mental illness were significantly different 
between Cameroonians and Canadians, with large differences between the means (Table II and the left side of Figure 5).

Similar differences between Americans and Cameroonians were observed on three of the items, but changes in wording for the remaining six items (in the original versus the version of the POSHA-MI(e) distributed in this study) made it impossible to use the American responses. Canadians' ratings of a mentally ill person's abilities were moderately positive for being able to interact socially, make friends, do well in school raise a family, get a job, do well at work, do any job the person wants, lead a normal life, and communicate effectively, compared to moderately negative ratings (and one neutral) for Cameroonians' ratings (right side of Table II).

Figure 5: Attitudes related to perceived abilities or potential, characteristics, and suggested actions for a person who is mentally ill: Respondents from Canada versus Cameroon combined, from English speakers versus French speakers combined, and from monolingual USA control respondents.

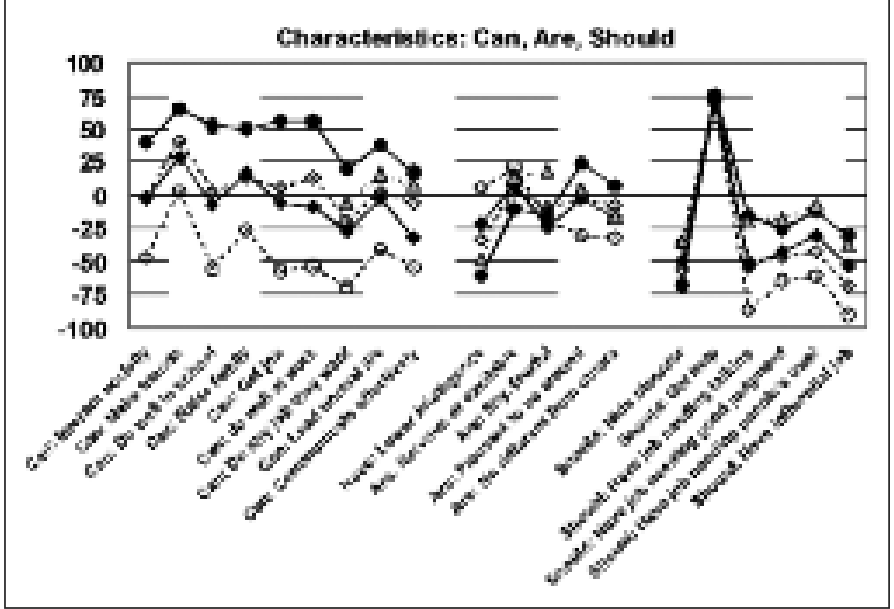

The middle of Figure 5 displays a similar pattern of less stigmatizing attitudes in Canada for lower-than-average intelligence, nervous/excitable, pleasant to be around, and no different from anyone else, significantly so for all but nervous/excitable. For shy/fearful, by contrast, Cameroon and Canada ratings were not different, but those for the USA and Canada-and English versus French speakers in Cameroonwere significantly different.

Finally, Canadians and Americans held significantly more positive views - though not above neutral ratings—on whether mentally ill persons should have jobs that require lots of talking, good judgment, and earning people's trust as well as influential jobs (right side of Figure 5). Canadians were less likely than Cameroonians to believe that mentally ill people should hide their disorder. All respondents believed that mentally ill people should get help for their problems (no significant differences across groups).

Taken together, Figures 2 to 5 graphically illustrate support for the hypothesis that differences in attitudes toward mental illness among English and French speakers in Cameroon and Canada were due primarily to country and not language. Also, these figures show that the American control group more closely paralleled the Canadian group than it did the Cameroonian, English, or French groups.

\section{Discussion}

\section{Overall public attitudes}

The study sought to confirm our hypothesis that people from Canada would have more positive public attitudes toward mental illness on the POSHA-MI(e) than people from Cameroon. Secondarily, it sought to confirm that filling out the questionnaire in the stronger of two languages, either English or French would not dramatically affect the results. Finally, it sought to confirm that attitudes of monolingual English-speaking American respondents would be more similar to Canadian respondents, irrespective of language, than to Cameroonian respondents, irrespective of language.

The participants were similar in age and years of education. Ottawa and Douala are both large cities. Douala is the largest city in Cameroon, with a population of approximately 2 million while the urban region of Ottawa has a population just over 1 million. Nonetheless, differences between Cameroon and Canada are large. 35,36,37 Differences in Canadian versus Cameroonian perceptions of their incomes relative to both friends and family and to all the people in their countries confirm that public perceptions are consistent with the fact that citizens of Cameroon have less disposable income than citizens of Canada. Table I also documents large differences between respondents from the two countries in terms of race and linguistic environment. The results show clearly that public attitudes toward mental illness also differ between the two countries, with Canadians reporting significantly more positive and less stigmatizing attitudes than Cameroonians. Table II shows that this was especially true regarding what respondents would do when interacting with a person with mental illness and what they believed about that person's potential and capabilities to interact with others, go to school, work, and raise a family. Among several important differences, Cameroonian respondents were much more likely than Canadian respondents to accept supernatural causes of mental illness, although the city dwelling participants in this study reported supernatural causes far less often than rural Cameroonians did in a study of epilepsy. ${ }^{24}$ Cameroonians also showed higher levels of concern about mental illness in religious leaders or the appropriateness of religious leaders in helping individuals with the problem. ${ }^{38}$ The pattern of Canadian participants being relatively accepting of various conditions is in line with findings from previous studies.

The American monolingual respondents, although selected primarily from previous samples using a different rating scale than the version of the $P O S H A-M I(e)$ in this study, manifested attitudes that were similar to the Canada sample and dissimilar to the Cameroon sample. Finally, the study also showed that differences between the linguistic groups in each country were smaller than those between countries (i.e., a higher number of significant differences occurred in the between-country comparisons than in between-language comparisons in Table II).

\section{Issues and cautions concerning the questionnaire} The study asked respondents to provide their opinions about mental illness as a generic entity, without regard to specific diagnoses. The authors recognize that public and professional attitudes toward schizophrenia, depression 
bipolar disorder, and so on are different. ${ }^{39}$ Pinpointing each mental illness in a cross-cultural instrument would make it much longer and would risk using terms unfamiliar to some participants. Translation of the names specific types of mental illness in a wide variety of languages would also be problematic. In fact, some difficulties were encountered in translating the generic term, "mental illness" into French. "Mental illness" is a more well-known term in English than in Canadian French. The French terms "maladie" or "trouble psychiatrique" are considered more severe than "troubles affectifs" which includes relatively mild disorders such as mild depression. All of these can covered by the single name, "mental illness," in English. The authors of this study settled on "maladie mentale." Perneger, Leplège, and Etter ${ }^{40}$ identified similar issues in wording in a careful investigation of the effects of different strategies for translating two psychometric instruments into French. Nevertheless, they found that the slight differences in translations made little difference in the empirical outcomes of the instruments. We concur with Rogler ${ }^{32}$ and Acquadro et al.31 that no translation can communicate exactly the same denotations and connotations as the original.

The data presented here are from convenience samples. The samples were sufficiently similar that comparisons could be made but we strongly emphasize that the specific attitudes reported should not be generalized to the broader populations in these countries. After a final version of the POSHA-MI(e) has been developed, future studies must compare samples of convenience with probability samples, selected to be as representative as possible of the populations studied.

We are unsure how to interpret the very large differences in responding time from Cameroonian respondents' means of 87 and 282 minutes, compared to Canadian respondents' means of 29 and 47 minutes, for English and French speakers, respectively. Most of the controls were not asked to report their responding time, but estimates from a few selected from samples taken after response time was added to the POSHA-MI(e) suggest a mean of about 25-30 minutes. It is possible, but unlikely, that the Cameroonians interpreted the question to mean, "How long did you have the questionnaire before giving it back." More likely, however, they reacted to surveys differently. It is more likely that respondents in that country were simply not accustomed to surveys and found them difficult and timeconsuming to complete. It is possible that the Cameroonian respondents treated the POSHA-MI(e) like a "test" and, therefore, thought about each item for a long time, looking for a "correct answer" before circling their rating. The much longer response times were observed in both English and French speaking Cameroonians. Finally, since the mean responding time for French speaking Canadians was over 60\% longer than for English speaking Canadians, it is possible that some of the same factors came into play in the French speaking Canadians. These unexpected results suggest that response time in international survey comparisons is worthy of additional study. It may also be appropriate to add instructions such as "Mark your first choice, the one that comes to mind immediately when you read each item. Please complete the entire questionnaire in one session."

\section{Conclusion}

As noted, large-scale efforts aimed at reducing the stigma associated with mental illness are ongoing. $41,42,43,44,45,46$ Developing a standard measure of public attitudes toward mental illness that can be used anywhere in the world among literate population, to document the impact of these efforts would be very useful. We believe that the POSHA$M I(e)$ can be that instrument. Next steps in its development will include further pilot testing of translations in various languages, in different countries, and in probability as well as convenience samples. Data from these investigations will be stored in an electronic database such that as more and more studies are carried out, comparisons of individual samples with the growing database sample will become possible. Also, once refined and completed, the final POSHA-MI can be used to measure the effectiveness of various strategies designed to mitigate stigma toward mental illness.

\section{Acknowledgements}

We are grateful to Joseph Lukong for his capable help in distributing questionnaires in Cameroon. We also thank Megan Freese for her assistance in data reduction and analysis.

\section{References}

1. Bohner G, Dickel N. Attitudes and attitude change. Annu Rev Psychol 2011;62:391-417.

2. Goffman E. Stigma: Notes on the management of spoiled identity. Englewood Cliffs, NJ: Prentice-Hall; 1963.

3. Angermeyer MC, Beck M, Matschinger H. Determinants of the public's preference for social distance from people with schizophrenia. Can J Psychiatry 2003;48:663-8.

4. Crisp AH, Gelder MG, Rix S, Meltzer HI, Rowlands OJ. Stigmatisation of people with mental illnesses. Br J Psychiatry 2000;177:4-7.

5. Sartorius N, Jablensky A, Korten A, Ernberg G, Anker M, Cooper $J E$, et al. Early manifestations and first-contact incidence of schizophrenia in different cultures: a preliminary report on the initial evaluation phase of the WHO collaborative study on determinants of outcome of severe mental disorders. Psychol Med 1986;16:909-28.

6. Thompson G. The burden of mental illness in Alberta: an overview of research and the views of Albertans. Commissioned by the Alberta Provincial Mental Health Advisory Board for "Health Summit '99'", 1999.

7. Thompson AH, Stuart H, Bland R, Arboleda-Florez J, Warner R, Dickson RA. Attitudes about schizophrenia from the pilot site of the WPA worldwide campaign against the stigma of schizophrenia. Soc Psychiatry Psychiatr Epidemiol 2002;37:47582.

8. DiLorio C, Shafer P, Letz R, Henry T, Schomer D, Yeager K. The association of stigma with self-management and perceptions of health care among adults with epilepsy. Epilepsy Behav 2003;4:259-67.

9. World Health Organization (WHO). Atlas: epilepsy care in the world 2005 [Internet]; 2005 ILAE/IBE/WHO Global Campaign Against Epilepsy. [cited 2012 Mar 2]. Available from http://www. who.int/mental_health/management/globalepilepsycampaign/en/. 10. Herek GM, Capitanio JP, Widaman KF. HIV-related stigma and 
knowledge in the United States: prevalence and trends, 1991 1999. Am J Publ Health 2002;92:371-7.

11. Maj M, Satz P, Janssen R, Zaudig M, Starace F, D'Elia L, et al. WHO Neuropsychiatric AIDS study, cross-sectional Phase II: neuropsychological and neurological findings. Arch Gen Psychiatry 1994;51:51-61.

12. Hebl MR, Heatherton TF. The stigma of obesity in women: The difference is black and white. Pers Soc Psychol Bull 1998;24, 41726.

13. Puhl R, Brownell KD 2001; Bias, discrimination, and obesity. Obes Res. 1998;9:788-805.

14. Al-Khaledi M, Lincoln M, McCabe P, Packman A, Alshatti T. The attitudes knowledge and beliefs of Arab parents in Kuwait about stuttering. J Fluency Disord 2009;34:44-59.

15. Betz IR, Blood GW, Blood IM. University students' perceptions of pre-school and kindergarten children who stutter.J Commun Disord 2008;41:259-73.

16. MacKinnon SP, Hall S, MacIntyre PD. Origins of the stuttering stereotype: Stereotype formation through anchoring-adjustment.J Fluency Disord 2007;32:297-309.

17. Van Borsel J, Verniers I, Bouvry S. Public awareness of stuttering. Folia Phoniatr Logop 1999;51:124-32.

18. Kessler RC, McGonagle KA, Zhao S, Nelson CB, Hughes M, Eshleman S, et al. Lifetime and 12-month prevalence of DSM-III-R psychiatric disorders in the United States. results from the National Comorbidity Survey. Arch Gen Psychiatry 1994;51:8-19.

19. Link BG, Struening EL, Rahav M, Phelan JC, Nuttbrock L. On stigma and its consequences: Evidence from a longitudinal study of men with dual diagnoses of mental illness and substance abuse. J Health Soc Beh 1997;38:177-90.

20. Rao D, Feinglass J, Corrigan P. Racial and ethnic disparities in mental illness stigma. J Nerv Ment Dis 2007; 1 95:1020-3.

21. Papadopoulos C, Leavey G, Vincent C. Factors influencing stigma: A comparison of Greek-Cypriot and English attitudes towards mental illness in north London. Soc Psychiatry Psychiatr Epidemiol 2002;37:430-4.

22. Pescosolido BA, Olafsdottir S, Martin JK, Long JS. CrosS-cultural aspects of the stigma of mental illness. In: Arboleda-Florez J, Sartorius N, editors. Understanding the stigma of mental illness: theory and interventions. Chichester, England: John Wiley \& Sons. 2008; p. 19-36.

23. Chase E, Aggleton P. 2001 Global: stigma, HIVIAIDS and prevention of mother-to-child transmission: a pilot study in Zambia, India, Ukraine and Burkina Faso. United Nations Children's Fund (UNICEF) / The Panos Institute; 2001.

24. Njamnshi AK, Tabah EN, Yepnjio FN, Angwafor SA Dema F, Fonsah $J Y$, et al. General public awareness, perceptions, and attitudes with respect to epilepsy in the Akwaya Health District, South-West Region, Cameroon. Epilepsy Behav 2009;1 5:179-85.

25. Shibre T, Negash A, Kullgren G, Kebede D, Alem A, Fekadu A, et al. Perception of stigma among family members of individuals with schizophrenia and major affective disorders in rural Ethiopia, Soc Psychiatry Psychiatr Epidemiol. 2001;36:299-303.

26. Couture SM, Penn DL. Interpersonal contact and the stigma of mental illness: a review of the literature. J Ment Health 2003;12:291-305

27. Rabkin J. Public attitudes toward mental illness: a review. Schizophr Bull 1974;1:9-33

28. Van Brakel WH. Measuring health-related stigma—a literature review. Psychol Health Med 2006; 1 1:307-34.

29. Hanson MD, Johnson S, Niec A, Pietrantonio AM, High B, MacMillan
H, et al. Does Mental illness stigma contribute to adolescent standardized patients' discomfort with simulations of mental illness and adverse psychosocial experiences? Acad Psychiatry 2008;32:98-103.

30. Yang LH, Link BG, Phelan JC. Stigma measurement approaches: conceptual origins and current applications. In: Arboleda-Flórez J Sartorius $N$, editors. Understanding the stigma of mental illness: Theory and interventions. New York: John Wiley \& Sons. 2008; p. $175-$ 92.

31. Acquadro C, Conway K, Hareendran A, Aaronson N. Literature review of methods to translate health-related quality of life questionnaires for use in multinational clinical trials. Value Health 2008;1 1:509-21.

32. Rogler, LH. Methodological sources of cultural insensitivity in mental health research. Am Psychol 1999;54:424-33.

33. Gravetter J, Wallnau LB. Statistics for the behavioral sciences. 8th ed., Belmont, CA: Wadsworth Centage Learning; 2009.

34. Cohen J. Statistical power for the behavioral sciences, 2 nd ed. Hillsdale, NJ: Erlbaum; 1988.

35. Foreign \& Commonwealth Office [Internet] 2011. [cited 2012 Mar 2]. Available from http://www.fco.gov.uk/en/travel-and-livingabroad/travel-advice-by-country/country-profile/sub-saharanafrica/cameroon.

36. Statistics Canada [Internet]. 2011. [cited 2012 Mar 2]. Available from http://wwwl2.statcan.ca/english/profil01/CP01/Details/Page.cfm? Lang $=E \& G e o l=C M A \& C o d e 1=505 \_\& G e 02=P R \& C o d e 2=35 \&$ Data $=$ Count\&SearchText $=$ ottawa\&SearchType $=$ Begins $\&$ SearchPR $=0$ $1 \& B 1=$ All\&Custom $=$

37. US Census Bureau. [Internet]. International Data Base (IDB). 2011 [cited 2011 Sep 30]. Available from http://www.census. gov/ipc/www/idb/country.php.

38. Song E. Mentally ill: a forgotten social class in Cameroon. African Outlook. 20113 Mar. [cited 2012 Mar 2]. Available from http://www.africanoutlookonline.com/index.php?option=com content\&view=article\&id=1245: mentally-ill-a-forgotten-social-classin-cameroon\&catid=96:allcomers\&Itemid $=54$.

39. Ross MGN, Windell D, Manchanda R. Examining differences in the stigma of depression and schizophrenia. Int J SocPsychiatry in press. Doi 0020764010387062.

40. Perneger TV, Leplège A, Etter JF. Cross-cultural adaptation of a psychometric instrument: two methods compared. J Clin Epidemiol 1999;5:1037-46.

41. Angermeyer MC, Matschinger H, Corrigan PW. Familiarity with mental illness and social distance from people with schizophrenia and major depression: testing a model using data from a representative population survey. Schizophr Res 2004;69:175-82.

42. Corrigan PW, Rafacz JD, Hautamaki J, Walton J, Rüsch N, Rao D, et al. Changing stigmatizing perceptions and recollections about mental illness: the effects of NAMI's In: Our Own Voice. Community Ment Health J 2010;46:517-22.

43. Gaertner SL, Mann JA, Dovidio JF, Murrell AJ, Pomare M. How does cooperation reduce intergroup bias? J Pers Soc Psychol 1990;59:692-704.

44. Luty J, Rao H, Arokiadass SMR, Easow JM, Sarkhel A. The repentant sinner: methods to reduce stigmatised attitudes towards mental illness. Psychiatric Bull 2008;32:327-32.

45. Penn DL, Corrigan PW. The effects of stereotype suppression on psychiatric stigma. Schizophr Res 2002;55:269-76.

46. Penn DL, Kommana S, Mansfield M, Link BG. Dispelling the stigma of schizophrenia: II. the impact of information on dangerousness. Schizophr Bull 1999;25:437-46. 